\title{
Validierungen in der Zahnarztpraxis
}

Mit der Validierung von Aufbereitungsprozessen in der Zahnarztpraxis befasst sich die Firma ValiTech in Deutschland bereits seit 1998. Seitdem hat sich das Unternehmen zum Marktführer unter den herstellerunabhängigen Validierern im niedergelassenen Bereich entwickelt. Aufgrund des hohen Begehungsdruckes in vielen Regionen Deutschlands hat der Freie Verband Deutscher Zahnärzte (FVDZ) eine Rahmenvereinbarung zur Validierung von Aufbereitungsprozessen in der Zahnarztpraxis abgeschlossen. Diese Vereinbarung ermöglicht FVDZ-Mitgliedern Rabatte auf den Rechnungspreis von bis zu 15 Prozent, je nach Auftragsvolumen. So kann eine Praxis mit drei Geräten (Thermodesinfektor, Kombinationsgerät, Sterilisator) bei einer Erst-Validierung bis zu 290 Euro einsparen, bei einer Re-Validierung bis zu 160 Euro. Dabei kann ValiTech stets eine behördliche Akzeptanz der Validierungsberichte gewährleisten.

Als akkreditiertes Prüflabor validiert ValiTech unabhängig vom Gerätehersteller die Prozesse Reinigung/Desinfektion, Siegelprozess und Sterilisation sowie Aufbereitungsprozesse mit Kombinationsgeräten. Durch eine regelmäßige Kommunikation mit den Begehungsbehörden kennt das Unternehmen die Anforderungen an die Validierung in allen Regionen Deutsch- lands. Darüber hinaus setzt ValiTech als erste Firma in Deutschland bei der Überprüfung der Reinigungsleistung die innovative Fluoreszenzspektroskopie als Messverfahren in Verbindung mit der oPA-Methode ein, und erfüllt so schon heute die zukünftigen Standards.

Neben der Validierung von Aufbereitungsprozessen sind auch weitere für die Zahnarztpraxis relevante Laborleistungen möglich. ValiTech stellt Testkits für Routinekontrollen der Reinigungsleistung in Thermodesinfektoren und Kombinationsgeräten zur Verfügung. Zudem kann ValiTech mikrobiologische Analysen des Einheitenwassers zahnmedizinischer Behandlungseinheiten nach RKI-Richtlinie durchführen - ein Thema, das die Begehungsbehörden zunehmend beachten.

Der FVDZ hat den Rahmenvertrag mit ValiTech auf Bundesebene seit 1. Juli 2016.

Weitere Infos gibt es unter www.valitech.de, info@valitech.de oder per Telefon unter 03322 27343-0. Die Kontaktaufnahme mit der Firma ValiTech ist auch über ein Formular auf der FVDZ-Homepage möglich.

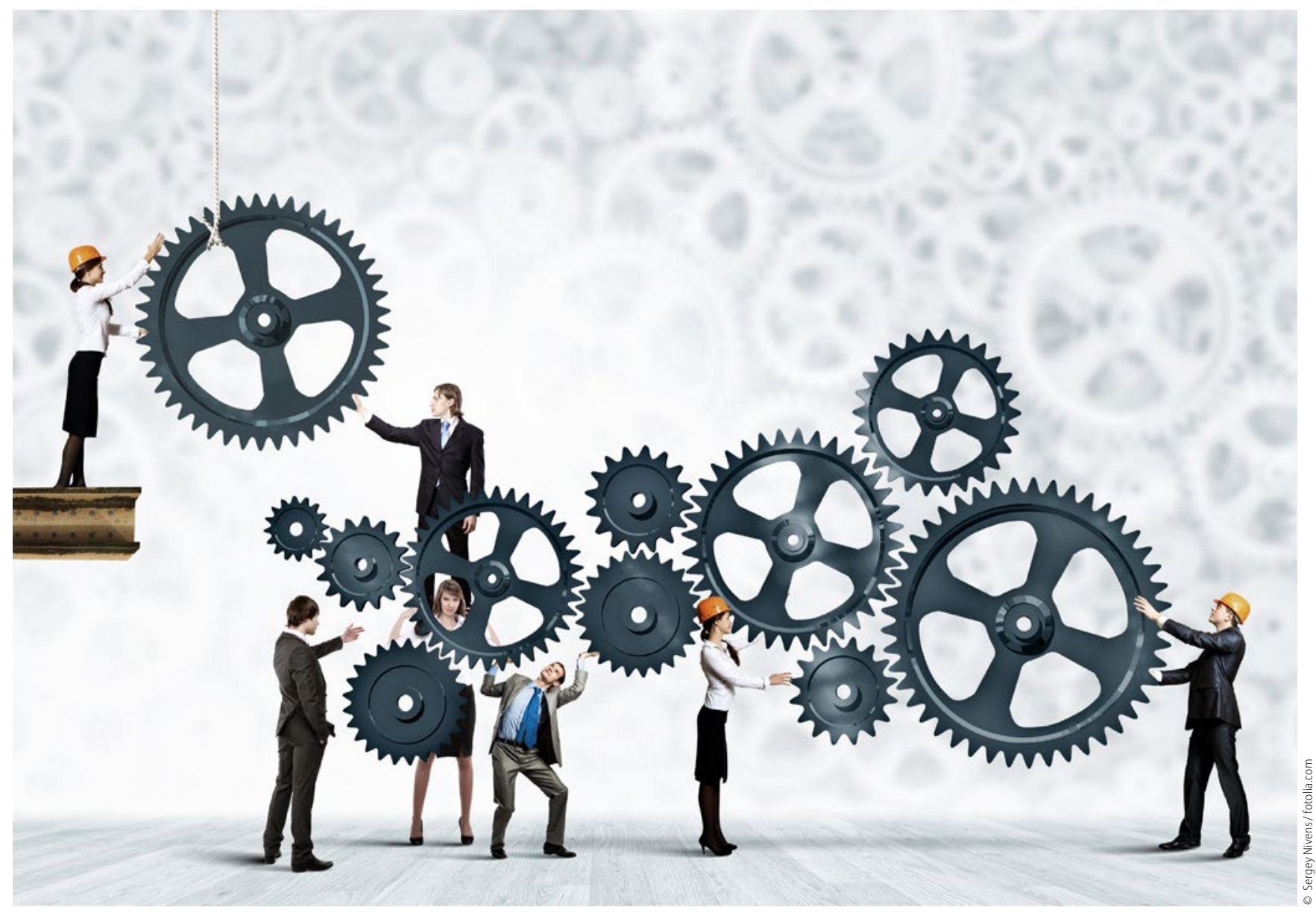

